\title{
Eco-92: avanços e interrogações
}

\section{WASHINGTON NOVAES}

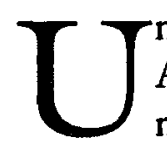

m evento como a II Conferência das Naçóes Unidas sobre Meio Ambiente e Desenvolvimento pode, deve e precisa ser visto por muitos ângulos. Cada um deles revelará um pedaço da história $\mathrm{e}$ ajudará a entender nuances e minúcias importantes para a apreensão das grandes questões globais. A chamada Eco-92 tem história c desdobramentos importantes dos pontos de vista científico, diplomático, político, social e da comunicação. $\mathrm{E}$ ainda exige uma compreensão específica a partir de uma realidade brasileira. Da mesma forma que pressupóe abordagens apropriadas para cada um dos grandes temas da Conferência.

Pode-se começar pelo tema das mudanças climáticas, uma das negociações mais complexas e difíceis.

Já nas discussões preparatórias de Nova York, $\mathrm{cm}$ abril/maio, ficará evidente que muitas das divergências seriam na verdade insuperáveis, dados certos fatores de ordem política e econômica, numa fase de transição para uma nova ordem mundial. Especialmente nos Estados Unidos, um dos principais atores no cenário.

Já enfrentando os problemas da recessão $e$ do desemprego num ano de campanha presidencial, os EUA vêem-se às voltas também com a necessidade de desmontar parcialmente o complexo industrial militar, inviabilizado por falta de objetivos. A desmontagem, entretanto, agravaria a recessão e o desemprego. Não por acaso, um Escritório de Conversáo criado pelo Congresso e entregue à direção do Pentágono só utilizou em 1991 metade dos 200 milhóes de dólares que lhe foram atribuídos. Por isso, em lugar de desativaçáo, aprovou-se a construção de mais dois submarinos Seawolf, ao custo de 3 bilhóes de dólares. Embora năo tenham alvos, os submarinos asseguram 20 mil cmpregos. Da mesma forma, aprovou-se a construção de 5 avióes Stealth, ao custo de 4 bilhōes de dólares, porque asseguram milhares de ocupaçôes na Califórnia. "Temos de reconhecer que não estamos preparados para a paz", afirmou dramaticamente um senador, na primeira página do New York Times, ao discutir a impressionante perda de competitividade da economia norte-americana diante da alemã e da japonesa nos últimos $\mathbf{3 0}$ anos. 
Nesse quadro, como pensar que o ator principal na questáo das mudanças climáticas aceitasse o papel que lhe cabia - o da maior quota na redução da emissão de poluentes atmosféricos que contribuem para o cenário em que se discutem as mudanças? Como pensar $\mathrm{em}$ fixação de níveis e datas para reduzir emissão de poluentes, se poucas semanas antes da abertura da Conferência do Rio de Janeiro a Presidência dos Estados Unidos dera a vitória ao Escritório de Qualidade liderado pelo vicepresidente Dan Quayle, em sua disputa com a Agência de Proteçáo Ambiental, na questáo do aumento de poluentes da atmosfera? A EPA exigia que as indústrias poluidoras continuassem obrigadas a comunicar em audiências públicas seus aumentos na emissão de poluentes. Quayle argumentava que, numa hora de recessão e descmprego, cra prioritário aumentar a produçáo, ainda que a certos custos ambientais. Ganhou Quayle.

Acentuava-se uma tendência, já esboçada dois meses antes em outas questóes. Como foi o caso do buraco na camada de ozônio sobre o Ártico. O governo norte-americano recusava-se a antecipar o final da produçáo dos gases CFC, principais responsáveis pelo csgarçamento da camada, porque a conversão para outras tecnologias custaria muitas dezenas de bilhões de dólares. E penalizaria principalmente o Pentágono, a quem se atribui quase $40 \%$ dos gases. Quando a NASA deixou vazar a informaçáo de que o buraco na camada se ampliava $\mathrm{e}$ fazia crescer o risco de câncer de pele para uma parte da populaçáo dos próprios Estados Unidos, na costa Leste, o governo imediatamente mudou de posição, antecipando o final para 31 de dezembro de 1994. Mas o diretor da NASA perdeu imediatamente seu emprego. $\mathrm{E}$ a indústria química obteve, de imediato, uma compensação que pleiteava: a aferição da concentração de agrotóxicos em alimentos deixa de ser feita na origem, no produto bruto, e passa a ser feita na prateleira, na hora do consumo. Jogo duro, jogo pesado.

Nesse cenário, era previsível que os EUA endurecessem a posição nas negociaçóes de Nova York. Mas náo eram a única resistência. A comunidade científica japonesa, por exemplo, mal se encerrara a reuniáo preparatória de Nova York, afirmou, sem disfarces, que dificilmente o Japáo terá como cumprir o objetivo de chegar ao ano 2000 sem últrapassar o nível de emissão de poluentes atmosféricos atingido em 1990. Quando nada, porque, apesar de enormes esforços, o Japão foi o país que mais aumentou essas emissóes nos últimos anos.

Uma terceira resistência se localizava nos países exportadores de petróleo, principalmente árabes. Fundamentada em muitas razões que, 
vistas do ângulo interno de cada um desses países, não deixam de ter sua lógica. Argumentavam esses países, como primciro ponto, que a ciência ainda não tem certeza se as mudanças climáticas de fato cstáo acontccendo ou acontecerão. Como náo tem certeza quanto às causas $\mathrm{c} o s$ próprios formatos que sobreviriam. Se é assim, dizem, como accitar políticas que induzam à redução do consumo de combustívcis fósscis? Essa redução terá conseqüências muito graves para a receita cambial dos exportadores; reduzirá a possibilidade de desenvolvimento econômico e social; agravará os problemas da miséria; e, em última análisé, poderá até conduzir a resultados opostos aos desejados, intensificando a pressáo sobre outros recursos naturais. Da mesma forma, a proposta de criação de um imposto sobre o consumo de combustíveis fósseis - apresentada pcla Comunidade Econômica Européia, mas condicionada à accitaçáo por todos os países industrializados - transferiria todo o ônus de combate ao problema para os países exportadores de petróleo, com a reduçáo de consumo que se seguiria ao aumento de preços. Penalizaria pobres, em lugar dos ricos.

Aí estaria, para estes, o centro da questáo. Em lugar de transformaçóes profundas nas estruturas de produçâo - que custariam investimentos fortíssimos aos países industrializados - se estaria tentando minimizar as ameaças de mudanças climáticas à custa dos países mais pobres. Quando, na verdade - como observa o próprio relatório brasileiro para a Conferência -, mesmo que se pudesse resolver todos os problemas ambientais do chamado Terceiro Mundo, isso cm termos globais não faria diferença significativa.

Diante de tantas dificuldades, não espanta que os diplomatas tenham caminhado na reuniáo de Nova York para um texto conciliador, barroco, malabarístico mesmo, que estabelecia o objetivo de chegar a 2000 com o nível máximo de emissáo de poluentes de uma década antes. Mas sem fixar esse nível como obrigatório. Nem cstabclecer quotas por país.

Ainda assim, no Rio de Janeiro, as negociaçócs foram penosas. Até o último momento os países exportadores de petrólco tentaram vetar o texto proposto para a convençāo, embora já quase isolados nessa posiçăo. É certo que o próprio secretário interino do Meio Ambiente, Josć Goldemberg, apontava o texto da convenção como inócuo. Também o comissário da Comunidade Econômica Européia se recusara a comparecer ao Rio de Janeiro, pelas mesmas razões. Mas há visões diferentes.

Em primeiro lugar, como reconheceram os próprios cientistas brasileiros, na reunião de julho da SBPC, os países signatários da convenção 
ficaram obrigados de imediato - antes mesmo da ratificação da adesão pelos parlamentos nacionais, que levará uns 3 ou 4 anos - a comunicar a uma espécie de comitê provisório da convenção qualquer mudança no nível de emissões, os quantitativos, as espécies de poluentes. Estabeleceuse, assim, não só uma responsabilidade diferenciada por país, como se abriram caminhos que permitam daqui por diante tomadas de posição preventivas - reconhecendo que náo será preciso esperar que a catástrofe aconteça para que se aja.

Trata-se, por outro lado, do primeiro texto de direito internacional positivo sobre esse tema, que, com certeza, começará a inspirar decisóes tanto no âmbito interno como nas questóes transnacionais.

Vista do ângulo brasileiro, porém, a questáo continuou preocupante. Na mesma reunião da SBPC, por exemplo, os participantes do painel sobre mudanças climáticas alertaram para algumas questóes: $1^{\mathfrak{a}}$ ) não há consenso - que precisa ser buscado - na comunidade científica nacional quanto à matéria; $2^{\mathbf{a}}$ ) há fortes indícios de mudanças nos dados registrados pelo Departamento Nacional de Metcorologia nos últimos 30 anos, mas náo permitem conclusóes categóricas porque muitas estaçóes que reuniam até 60 e 70 anos de dados foram fcchadas, outras estão sucateadas e outras ainda se localizam em áreas onde a cxpansão urbana e o desmatamento alterara condiçóes e com certeza influenciaram mudanças; 3a) a imensa maioria dos cientistas brasilciros - fundamentais para desenvolver um programa nacional para o Mcio Ambiente, o Clima e as Mudanças Climáticas - está no exterior. Como levar adiante, nessas condiçóes, um programa adequado à realidade brasileira sob csse ângulo?

\section{A biodiversidade e o futuro}

Do ponto de vista dos interesses brasileiros, talvez a convenção sobre proteçáo da biodiversidade tenha sido o tema mais importante da Conferência, já que, como observa a diretoria do Jardim Botânico de Brasília, Anajúlia Heringer Salles, "em matéria de biodiversidade, o Primeiro Mundo somos nós". E, aí, o problema está não apenas na proteção dessa biodiversidade, que talvez chegue a uns $30 \%$ da biodiversidade global, mas nos formatos de apropriaçáo.

Na reunião de Nova York não houve acordo, tais as resistências, ainda que a primeira versáo proposta, que refletia principalmente as preocupaçóes da comunidade científica, houvesse sido abandonada e substituída por outro texto, redigido por diplomatas (daí a crítica de 
muitos cientistas de que a nova versão privilegia os aspectos cconômicos da questáo e relega a segundo plano a proteçáo da biodiversidade, que deveria ser um objetivo em si mesma).

Só numa reuniáo especial em Nairobi, já às vésperas de iniciar-se a Conferência do Rio de Janeiro, conseguiu-se chegar a uma proposta de convençáo, na qual a diplomacia brasileira teve forte influência.

Sob certos aspectos, trata-se de um avanço notável, um texto histórico mesmo, na medida em que estabelece novos princípios para algo - a apropriação de recursos naturais de um país por outro - que fora estabelecido há séculos, pela força das armas, primciro, $\mathrm{c}$ dos recursos financeiros e científicos, depois.

Ao estabelecer a soberania dos países detentores da biodiversidade sobre esses recursos e seu direito de participar dos resultados científicos e financeiros da exploraçáo, a convençáo aprovada no Rio de Janeiro muda a relaçáo de apropriaçáo entre países ricos c pobrcs.

Não é de estranhar, portanto, a recusa obstinada dos Estados Unidos em assinar a convenção, ainda que ao preço do isolamento diplomático. São as empresas norte-americanas as detentoras da maioria das patentes sobre conhecimentos dessa biodiversidade. O norte-americano Thomas Lovejoy, da Smithsonian Institution, estima em 200 bilhóes de dólares por ano o resultado da apropriaçáo da biodiversidade pelas indústrias química e farmacêutica.

Boa parte dos cientistas entende que, talvez, o principal mérito dessa convençáo assinada no Rio de Janeiro tenha sido o de "conscientizar o mundo" para a importância da questão. Scja a importância para a preservação de ecossistemas, seja porque dessa preservação dependerá o futuro, já que das espécies ainda desconhecidas (só foram descritos de 1,2 a 1,4 milhão dos 10 milhóes de espécies que se estima cxistirem) viráo os futuros materiais, medicamentos e alimentos

A propósito destes últimos, lembra o espanhol José EsquinasAlcazar, responsável pelo Comitê de Recursos Genéticos da FAO, que mais da metade das variedades dos 20 alimentos mais importantes para a humanidade já desapareceu desde o início deste século, aí incluídos arroz, trigo, milho, batata, feijāo, ervilhas, centeio c cevada. No mesmo período, os Estados Unidos perderam $80 \%$ de suas variedades na horticultura e na fruticultura, cada uma delas, tal como os outros alimentos, sendo uma combinaçáo única de genes responsáveis pelo sabor, teor nutritivo, resistência a pragas, adaptaçáo ao solo, resistência a fenômenos climáticos, etc. A padronização de sementes, relacionada com técnicas de 
dominação de mercados, responde por grande parte da perda. Mas a reposiçăo possível no futuro, que depende da preservaçáo da biodiversidade, está ameaçada.

Já no Rio de Janeiro, levantaram-se outras questōes, a propósito da convenção da biodiversidade, quase todas de ordem jurídica. Primeiro, porque tramita no Congresso Nacional brasileiro um projeto de novo Código da Propriedade Industrial, que, ao reconhecer o dircito de certos patenteamentos, pode anular as conquistas da convençăo. Segundo, porque está cm negociaçáo um novo acordo no âmbito do GATT (Acordo Geral de Tarifas e Comércio), que também prevê um capítulo sobre patentes, com os mesmos riscos.

A comunidade científica brasileira tem manifestado sua preocupação com essas questōes. Da mesma forma, têm-se levantado outros problemas de ordem prática.

Pergunta-se, por exemplo, de que formas práticas poderá sc valer um país para fiscalizar e assegurar sua soberania sobre as espécies. Como provar que esta ou aquela espécie utilizada com esta ou aquela finalidade por uma empresa de outro país foi retirada de seu território? E se não houver acordo quanto à participação nos resultados, entre a empresa detentora do conhecimento científico e o país soberano?

Outras possibilidades: se o Código da Propriedade Industrial for aprovado antes que entre em vigor a convençáo da biodiversidade, poderão ser reconhecidos milhares de patentes antes que se reconheçam os direitos nacionais à participação nos resultados; que regra prevalecerá? $\mathrm{E}$ que regras valerão para países, como os Estados Unidos, que nấo assinarem a convençáo? Como se resolveráo os conflitos? E quando entrar em vigor o acordo do GATT, que não prevê participação nos resultados científicos e financeiros?

De qualquer forma, pensam os cientistas, a convenção é um passo importante, embora um deles, o Prof. Otto Solbrig, de Harvard, tenha dito na SBPC que "em 1972, em Estocolmo, se disse a mesma coisa, enáo hove mudanças importantes".

A crítica das organizaçóes não-governamentais (ONGs) é mais severa. Além de náo aceitarem que se privilegiem os aspectos econômicos do problema, em detrimento da conservaçáo da biodiversidade por si mesma, entendem que a reivindicação de acesso às biotecnologias de ponta náo pode ser levada a sério, já que estamos abrindo máo dela no Código de Propriedade Industrial. E ainda que náo estivéssemos, a redução dos investimentos em ciência e tecnologia nos inabilita a absorver 
essas tecnologias. Além do mais, a ênfase nas tecnologias de ponta traria implícita a renúncia a outras tecnologias mais acessíveis, mais adcquadas à nossa realidade, e a projetos de desenvolvimento sustentávcl.

\section{Florestas e soberania}

Não foram muito diferentes as críticas dos ambientalistas à Declaraçáo sobre Florestas concertada no Rio de Janeiro. Segundo estes, a preocupação com o "manejo sustentado" dessas áreas na verdade apenas encobriria o propósito de exploração das florestas tropicais com fins econômicos e sem preocupaçóes ecológicas, partilhado por muitos países detentores dessas florestas e seus parceiros comerciais consumidores, como o Japão, principalmente.

Desde a reuniāo preparatória de Nova York, o tema se mostrava explosivo. Primeiro, porque a reivindicação de soberania quanto às florestas tropicais - colocada na mesa pelos respectivos países $\mathrm{c}$ afinal consagrada no documento do Rio de Janeiro - impedia até mesmo qualquer referência geográfica que pudesse caracterizar uma "intromissáo em assuntos internos". Segundo, porque para um grupo numeroso de países, liderado no Rio pela Malásia, a exploraçáo de madeiras tropicais é fonte importantíssima de recursos cambiais e agente econômico decisivo.

Do ângulo dos países desenvolvidos, principalmente Estados Unidos e Europa, o tema coloca-se de forma diferente. Seriam convenientes normas planetárias para evitar que o desmatamento $\mathrm{e}$ as queimas de florestas continuem a responder por uns $25 \%$ das emissốes de dióxido de carbono na atmosfera. E para impedir que prossiga o ritmo de devastaçáo atual, calculado em 17 milhôes de hectares/ano (contra 11 milhôes na década anterior), que leva à previsão da $\mathrm{ONU}$, de extinguirem-se cm 40 anos as florestas tropicais. Só na última década, a área coberta por florestas tropicais caiu de 18,8 para 16,8 milhóes de quilômetros quadrados (menos 200 milhóes de hectares). Uma perda irrcparável, já que nesses $20 \%$ das terras do Planeta ocupados por florestas se calcula que estejam entre 50 e $75 \%$ de todas as espécies vegetais e animais.

A discussáo fica ainda mais complicada quando alguns cientistas argumentam que, em termos de balanço do carbono, na verdade o desmatamento não teria conseqüências tão nefastas se acompanhado de replantio imediato, ainda que de espécies exóticas ou uniformes, já que no período de crescimento as árvores absorvem mais carbono do que emitem. Nesse caso, substituir uma floresta tropical adulta por uma floresta uniforme replantada teria, durante esse tempo de crescimento, conse- 
qüências até positivas quanto ao balanço do carbono. Restaria a questáo da biodiversidade.

A declaração do Rio de Janeiro procurou conciliar alguns desses ângulos - soberania, direito ao desenvolvimento, manejo sustentado. $\mathrm{E}$ a Agenda 21 previu investimentos anuais de 6,2 bilhões de dólares (ainda não-disponíveis), só na parte de cooperação internacional, para viabilizar o "desenvolvimento sustentável" das florestas. Em que consistiria ele?

Um documento do próprio Banco Mundial coloca em dúvida essa possibilidade. Seu autor, Arne Dalfelt, afirma no estudo Ecological Constraints to sustainable management of the tropical moist forest que "a floresta tropical úmida primária náo pode ser manejada de modo a que se assegure simultaneamente um lucro macro-econômico suficiente e a sustentabilidade do ecossistema como um todo". O desenvolvimento sustentável nessas áreas, em sua opinião, só seria possível se a cargo de populaçóes de baixa densidade e baixa tecnologia. Melhor seria, entende ele num plano mais amplo, conservar as florestas tropicais, dada sua importância para a biodiversidade, e cuidar do reflorestamento de áreas degradadas - tese esposada em parte por alguns países subdesenvolvidos, que perguntam: por que o Primeiro Mundo, em lugar de impor estratégias florestais ao Terceiro Mundo, não refloresta cle mesmo suas áreas?

Críticas levadas à Conferência do Rio de Janciro por ONGs asiáticas - que estão testemunhando a destruição de florestas no scu subcontinente - reafirmam a outra parte das obscrvaçócs. Para clas, os projetos de "desenvolvimento sustentável" nas florestas tropicais asiáticas, apoiados pelo próprio Banco Mundial, na verdade resultaram em mais desmatamento, e não menos. Além disso, geraram conflitos com índios, deslocaram milhóes de agricultores e ameaçam outros milhōes, principalmente na Tailândia e Indonésia, onde se prevê a substituição de florestas nativas por reflorestamentos.

O tema das florestas - não é dificil concluir - continuará gerando polêmicas. E só pode ter solução num contexto capaz de propor mudanças muito mais profundas que as consensadas na Rio 92 (cmbora estas não sejam desprezíveis).

Mesmo entre cientistas, subsistem divergências, como ficou evidenciado nas discussóes promovidas pela SBPC. Ali, por exemplo, o Prof. Otto Solbrig, de Harvard, colocou suas dúvidas quanto a uma relaçáo direta entre supressão de florestas tropicais e mudanças climáticas em âmbito planetário. A seu ver, o desmatamento afeta local e regional- 
mente. E a substituição de florestas tropicais na Ásia c África por florestas secundárias pode até ser vantajosa, de alguns pontos de vista.

Já o pesquisador Philip Fearnside entende quc, cnquanto não se definir com precisão o que é manejo sustentado de florestas, o conccito na verdade continuará apenas justificando o desmatamento. Pior ainda, um desmatamento que interessa fundamentalmente aos segmentos mais ricos da população da Amazônia, por exemplo (que respondem por $70 \%$ da devastação), e não aos mais pobres.

A seu ver, dois caminhos poderiam ser produtivos: $\left.1^{\circ}\right)$ a agrossilvicultura em pequena escala; $2^{\circ}$ ) um sistema mundial que rendesse compensaçóes financeiras a quem preservasse florestas.

\section{Onde entram as pessoas}

Como se tratava de uma conferência sobre meio ambiente $\mathrm{c}$ descnvolvimento, o encontro do Rio de Janeiro foi todo cle perpassado pela questão populacional. Como reduzir a pressão sobre recursos naturais se a população do Planeta não cessa de crescer? Como enfrentar problemas ambientais em âmbito planetário se uma parte considerável deles tem relações estreitas com os problemas da miséria?

Muitos dos documentos levados à Conferência, assim como muitos dos pronunciamentos de delegados e chefes de Estado, centraram-se nessa questão.

Somos hoje, diz um relatório recente do Fundo das Naçōes Unidas para a Populaçáo, quase 5,5 bilhóes de pessoas e chegaremos a 6,26 bilhóes na virada do século. Em 2050, seremos pclo menos 10 bilhôes. Um século mais tarde, numa projeção otimista, 11,6 bilhóes; na estimativa pessimista, 20 bilhôes de pessoas.

Até aqui, vem-se reduzindo velozmente o intervalo de tempo necessário para dobrar a população. Levamos milhốes de anos para chegar a um bilhão de pessoas, em 1830. Mas não precisamos nem de um século para dobrar de novo a população, $\mathrm{cm} 1927$. Nos 65 anos seguintes, até hoje, quase triplicamos os habitantes do Planeta. Como continuam nascendo três crianças por segundo, a cada dia se somam mais de $250 \mathrm{mil}$ pessoas, o que representa quase 100 milhões por mês e quase um bilhão numa década. Com a agravante de que $83 \%$ do crescimento populacional previsto se darão no chamado Terceiro Mundo, onde já se concentram $77 \%$ da populaçáo da Terra, com apenas $15 \%$ da renda global (náo por acaso, 70 milhôes de pessoas já migraram para os países mais ricos nas últimas décadas). 
Por onde enfrentar a questão, se a ética impede que se pense em populaçáo em termos de poder (desejando que cresça), ou cogitando simplesmente de reduzi-la a qualquer preço, para que não afete a segurança dos ricos? É preciso pensá-la em termos de dignidade humana, de adequaçáo dos padróes civilizatórios às possibilidades de recursos e de equilíbrio da vida na Terra. Profundidades das quais a Eco-92 esteve bastante longe.

Um dos caminhos com certeza passa pela correçáo dos desequilíbrios regionais de renda, causa fundamental das migraçóes e do inchaço das periferias de metrópoles, onde o problema se agrava, porque mulheres e crianças, antes também fator de produção, passam a ser, fora do mercado de trabalho, apenas fator de consumo. Outro caminho exige avanços rápidos e transformadores via educação. Um estudo da própria ONU mostra que nos países mais pobres a taxa de fertilidade entre as mulheres mais pobres e analfabetas chega à média de seis filhos; entre as que freqüentaram escola, dois filhos. $\mathrm{Na}$ América Latina, o aumento recente da escolaridade entre mulheres já conduziu a uma queda entre $\mathbf{4 0}$ e $60 \%$ na natalidade.

No caso brasileiro, o problema vem decrescendo. Era de 6,16 na década de 40 o número médio de filhos por mulher. Baixou para 4,35 em 1980 e para $3,16 \mathrm{em} \mathrm{1990.} \mathrm{É} \mathrm{provavel} \mathrm{que} \mathrm{continue} \mathrm{a} \mathrm{cair,} \mathrm{porque,}$ segundo o IBGE, mais de $40 \%$ das mulheres em idade fértil já foram esterilizadas ( $71,3 \%$ em Goiás). Embora esses números tragam à discussáo aspectos éticos dessa esterilizaçáo em massa, ć inegável que demonstram, no absoluto, uma tendência à redução do problema. $O$ equílibrio será atingido quando cada mulher tiver em média apenas dois filhos, a chamada taxa de reposição (um para a mulher, outro para o homem, sem crescimento no global).

No mundo como um todo, entretanto, não é essa a tendência. Na última década, enquanto a população decresceu, se estabilizou ou cresceu pouco no Primeiro Mundo (menos $\mathbf{0 , 3} \%$ na Alemanha, zero na Bélgica e Holanda, 1,6 na Grä-Bretanha), no Terceiro Mundo as taxas de crescimento atingiram mais de $\mathbf{4 0 \%}$ no Paquistáo, mais de 30 na Argélia e Bangladesh, quase 30 nas Filipinas.

É tema que vai incendiar as discussóes nos próximos anos. Mas que não teve avanços práticos na Conferência do Rio de Janeiro.

\section{Onde buscar recursos?}

A ausência de avanço nessa matéria deve-se, fundamentalmente, às 
enormes dificuldades na discussão dos recursos para o meio ambiente e o desenvolvimento, isto é, o financiamento da chamada Agenda 21.

Não falta quem considere puro blablablá tudo o que aconteceu no âmbito da Conferência oficial, quando nada porque, na hora de estabelecer os recursos financeiros para as centenas de páginas de programas da Agenda 21, os países mais ricos, na sua maioria, fugiram a compromissos - seja de quantitativos, seja de datas.

A partir de certo momento, quando a diplomacia tentava conseguir pelo menos um compromisso em torno do que já fora acertado há muitos anos - a contribuição de $0,7 \%$ do Produto Interno Bruto dos países do Primeiro Mundo - ficou claro que os países ricos preferem continuar como estáo: determinando, eles mesmos, qual é sua contribuiçáo e quais sáo os seus parceiros, em lugar de prover recursos para fundo c outros organismos internacionais que se comportariam segundo regras que thes fugiriam ao controle.

É certo que houve avanços. Multiplicaram-se os canais para captação e aplicação de recursos, fugindo ao canal único do Banco Mundial. Mas náo se conseguiu chegar nem perto dos objetivos propostos pela ONU e reiterados pelo secretário da Conferência, o canadense Maurice Strong.

Calculou a ONU que, para enfrentar hoje os problemas ambientais e da miséria no Planeta, são necessários em torno de 600 bilhóes de dólares por ano. Desse total, $80 \%$ teriam de ser providos pelos próprios países onde estáo os problemas. Restariam $20 \%$ ou 120 bilhôes de dólares/ano para a cooperação internacional, que, por várias formas, já destina hoje uns 50 bilhóes.

Dias e noites de negociaçóes para amarrar um compromisso de mais 70 bilhóes de dólares anuais foram inúteis. Nem mesmo a proposta de chegar a isso até o ano 2000 vingou.

Seria impossível? Strong não se cansou de dizer que se trata de decisáo política: o mundo continua aplicando mais de um trilhão de dólares anuais em despesas militares. Por que não poderia investir um décimo disso na soluçáo dos problemas ambientais e da miséria? Só os Estados Unidos tiveram em 1991 um orçamento militar próximo dos 300 bilhóes de dólares e ainda não chegaram à metade dos $0,7 \%$ ao ano do PIB para a ajuda internacional, seu compromisso de 12 anos atrás. Quanto ao Primeiro Mundo no seu conjunto, por que náo poderia destinar $0,1 \%$ do seu PIB de 15 trilhões de dólares à solução ambiental? 
Terá sido esse, provavelmente, o ângulo menos esperançoso da Conferência. Levando muitos observadores a temer que só a iminência de catástrofes possa produzir mudanças mais profundas de comportamento.

\section{Além das aparências}

Esse temor baliza, também, as críticas mais radicais dos ambientalistas que esperavam da Conferência questionamentos mais profundos, capazes de levar a transformaçóes decisivas nos modos de viver, nos padrốes civilizatórios, nas matrizes energéticas, nos padróes de consumo. Esperavam que os países ricos demonstrassem concretamente sua decisão de reduzir o nível de consumo de suas populaçóes (hoje, apontou o relatório brasileiro, um habitante do Primeiro Mundo tem um poder de impacto sobre os recursos naturais 25 vezes maior que o de uma pessoa do Terceiro Mundo). Esperavam caminhos para uma distribuição mais eqüitativa dos frutos do trabalho no mundo. A renúncia a formatos políticos, econômicos e sociais que colocam a vida em risco no Planeta.

Mas a Rio 92 ainda se pautou por critérios orientados pela convicção de que, com recursos financeiros e tecnologias adequadas, será possível reorientar a atividade humana e não ultrapassar os limites que nos ameaçam. Será possível?

Dispomos hoje de apenas $\mathbf{0 , 0 0 3 7 8 \%}$ da água do Planeta (o restante está nos oceanos, nas geleiras e em aqüíferos ainda inacessíveis), mas continuamos a poluí-la em proporçóes crescentes. A ciência prevê guerras pela água na África, no Oriente Médio, na Ásia. Embora o Brasil tenha uns $20 \%$ da água doce do Planeta, não escapamos a conflitos. E $60 \%$ das internaçóes hospitalares, aqui, decorrem de doenças de veiculação hídrica.

A desertificação avança à razão de 60 mil quilômetros quadrados por ano. $20 \%$ do solo fértil do nosso mundo já se perderam.

Se a concentração de carbono na atmosfera continuar crescendo $1 \%$ ao ano, como hoje, em 25 anos teremos uma concentração de poluentes no ar que será o dobro da de 1950. Com que consequiências?

Apesar de todas as restriçōes, a concentração de CFCs que esgarçam a camada de ozônio ainda sobe $5 \%$ ao ano. Cresce a ameaça sobre as populaçóes do Hemisfério Norte também.

$O$ arsenal nuclear acumulado continua a reservar o equivalente a 
alguns quilos de dinamite por habitante da Terra. Já temos 200 mil toneladas de lixo radiativo acumuladas e sem destino.

E assim por diante.

Quem será capaz de enfrentar e resolver tudo isso? Hoje, essa tarefa está entregue às instituições legadas pela Revolução Industrial - 0 Estado Nacional e as corporaçóes transnacionais, principalmente -, que não se têm revelado muito eficazes.

Seria preciso, com certeza, uma nova ética, fundada na solidariedade, e não na competição. Uma ética que com certeza incluirá o que vários estadistas - entre eles o ex-primeiro ministro Michel Rocard, da França, e o ex-presidente Miguel de la Madrid, do México - propuseram no Rio de Janeiro: um direito ambiental internacional, até mesmo "uma organização ambiental mundial", já que os fenômenos ambientais não obedecem a fronteiras geopolíticas ou administrativas. Como disse Rocard, se estamos "condenados a viver juntos, estamos condenados também a nos pôr de acordo juntos".

\section{O papel da comunicação}

Nesse quadro, será decisivo o papel da informação e da comunicaçáo de massa.

Primeiro, para que o mundo todo possa refletir sobre alguns temas já colocados na mesa e que já estão influindo na gestação da nova ordem mundial. A reunião da SBPC tratou de alguns deles.

Por exemplo: a lógica do mercado combina necessariamente com a direçáo desejada, de implantar o chamado desenvolvimento sustentável?

Como conciliar planejamento global com a necessidade de participação e decisão comunitária? Como conciliar a descentralização do poder com a necessidade de que as açốes individuais năo prejudiquem o equilíbrio global?

Como fazer para que os bilhóes de deserdados da sorte sejam ouvidos antes das decisóes que pretendem definir seus destinos?

Como se criar sociedades em que não sejam apenas alguns a decidir e a fazer pelos demais, e sim sociedades capazes de mobilizar todas as pessoas, que dispensem as cabeças supostamente iluminadas? 
Muitas dessas indagaçóes perpassam a análise crítica da Eco-92 feita durante a reunião anual da SBPC em São Paulo. Ao lado de várias outras:

Como acreditar que se estabelecerá um fluxo de informação do Primeiro para o Terceiro Mundo, sem ônus, se informação é poder? A questão tecnológica é antes de tudo social e política, mais que científica.

Mas ainda que se estabelecesse o fluxo de informações tecnológicas e científicas, o que autoriza supor que as tecnologias do Primeiro Mundo sejam adequadas às necessidades do Terceiro? O próprio rclatório brasileiro para a Conferência diz que os problemas ambientais decorrem da pobreza e do mau uso da riqueza, que a maior parte dos problemas já vem embutida nos modelos de desenvolvimento e nas tecnologias importadas.

Se é assim, como supor que o bilháo de pessoas desempregadas ou subempregadas no Terceiro Mundo será incorporado ao desenvolvimento sustentável? A Agenda 21 sequer trata do tema. E sem a incorporaçáo, como admitir que se caminhará para a soluçáo dos problemas já vistos?

Por outro lado, o desenvolvimento sustentável pressupóe não apenas tecnologias limpas e recursos financeiros, mas também a redução do consumo perdulário do Primeiro Mundo e dos segmentos favorecidos do restante do Planeta.

"A desigualdade inviabiliza o desenvolvimento sustentável", concluíram os cientistas na SBPC. A sustentabilidade năo será conseqüência apenas de melhorias no meio ambiente, nem de avanços tecnológicos, $e$ sim da prevalência da ética da igualdade.

O segundo ângulo pelo qual a informação/comunicação será decisiva está em que os avanços sociais dependerão fundamentalmente do acervo de informaçóes científicas que chegue ao conhecimento das sociedades. A informação é que transforma a consciência. A consciência transformada é que faz mover governos.

Coloca-se, portanto, o problema da relaçáo entre ciência e poder, e da relaçáo do poder com a comunicação de massa.

A mais extraordinária conquista da Conferência do Rio de Janeiro foi a exposiçáo que deu, no mundo todo, através dos meios de comunicação, a problemas ambientais e científicos, em geral confinados a pequenos espaços $\mathrm{e}$ abordagens superficiais. Foi haver incorporado a questáo ambiental ao cotidiano dos cidadáos comuns, que puderam avançar 
sua consciência. Foi haver incorporado o meio ambicnte ao jogo democrático.

Mas o exemplo citado atrás - as informaçōes sobre o avanço do buraco na camada de ozônio do Ártico - realça dramaticamente os problemas da relação ciência/poder/comunicação de massa, da qual dependeremos cada vez mais decisivamente.

E aí duas tarefas se colocam para os cientistas: $1^{a}$ ) lutar, ao lado da sociedade e dos profissionais da área, pelo reconhecimento do direito social à informação (que deveria ser escrito na Constituição, para permitir a regulamentação por leis; hoje a sociedade brasileira não tem direitos em matéria de informaçáo); $2^{a}$ ) lutar para que a comunidade científica perca seu pavor ao risco de superficialidade, generalização, simplificaçáo e seja capaz de comunicar-se com a sociedade para informá-la sobre as questóes vitais.

Se não for assim, a vitória maior da Conferência do Rio de Janeiro - $o$ avanço na informaçáo $e$ na consciência social - correrá o risco de perder-se. Teremos de esperar pelas catástrofes para nos mover.

Washington Novaesé jornalista e secretário estadual de Meio Ambiente, Ciência e Tecnologia de Brasília (DF). 